\title{
ResearchArticle
}

\section{Study of genotype dependent response against treatment of As+Se in barley}

\author{
KULDEEP KUMAR, MADHU RANI AND A.K. SRIVASTAVA
}

\begin{abstract}
SUMMARY
The present paper deals with the genotoxicity assessment of five partially tolerant and five non-tolerant accessions of Hordeum vulgare (barley) for the heavy metals arsenic and selenium in combination. The genotype dependent response was studied using root meristem cytology. These two heavy metals in combination influenced mitotic division inducing various kinds of anomalies.
\end{abstract}

Key Words : Hordeum vulgare, As+Se, Genotoxicity

How to cite this article : Kumar, Kuldeep, Rani, Madhu and Srivastava, A.K. (2015). Study of genotype dependent response against treatment of As+Se in barley. Internat. J. Plant Sci., 10 (1): 64-69.

Article chronicle : Received : 21.08.2014; Revised : 28.11.2014; Accepted : 14.12.2014

\section{MEMBERS OF THE RESEARCH FORUM}

Author to be contacted :

KULDEEP KUMAR, Department of Botany, C.C.S. University, MEERUT

(U.P.) INDIA

Email: kkbalyan1@gmail.com

Address of the Co-authors:

MADHU RANI AND A.K. SRIVASTAVA, Department of Botany, C.C.S.

University, MEERUT (U.P.) INDIA 